\title{
Study of Outcome of Children with Bronchial Asthma with Special Reference to Pulmonary Function Test
}

\author{
Naveen Ganapan and Charul Mehta* \\ Department of Pediatrics, India
}

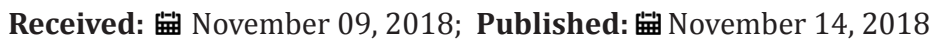

*Corresponding author: Charul Mehta, Department of Pediatrics, India

\section{Abstract}

Aim: To study the disease control via pulmonary function test with usage of bronchodilators in bronchial asthma patients.

Setting and design: Prospective cohort study done at Asthma clinic, Dept of pediatrics, BJ medical college, Ahmedabad.

Materials and Methods: Patients enrolled in this study were from asthma clinic BJ medical college and Civil hospital. Pulmonary function test was done on total of 91 known asthma patients. Here three parameter of lung function is taken in to account. Percentage OD FEV1 of predicted, FEV1:FVC Ratio and PEFR, its effect on bronchodilators on PEFR.

Results: Out of 91 patients, 72 (79.25\%) patients had almost normal pulmonary function. Only 1 patient had severe restriction of pulmonary function and 18 patients had moderate restriction of lung function. All patients shows improvement in PEFR more than $20 \%$ after bronchodilators therapy which is suggestive of reversible air flow limitation.

Keywords: PEFR; $\mathrm{FEV}_{1}$; FVC

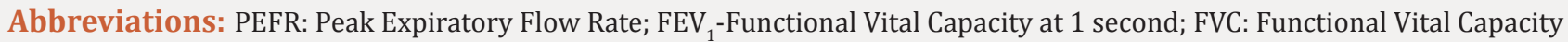

\section{Introduction}

Asthma is a chronic inflammatory disorder associated with airway hyper responsiveness that leads to recurrent episodes of wheezing, breathlessness, chest tightness and coughing in night or in the early morning. These episodes are usually associated with wide spread, but variable, airflow obstruction within the lung that is often reversible either spontaneously or with treatment. Spirometry helpful in clinically diagnosis of asthma is in doubt, improvement in FEV more than $12 \%$ after inhaled short acting bronchodilators establishes the diagnosis of asthma, $\mathrm{FEV}_{1} / \mathrm{FVC}$ ratio less than 0.80 suggestive of significant airflow obstruction. Exercise challenge, worsening in FEV > 15\% suggestive of exercise induced asthma.

\section{Materials and Methodology}

a. Setting and Design: Prospective cohort at Asthma clinic BJ medical college and Civil Hospital.

b. Study period: January to September 2018 c. Inclusion Criteria: Diagnosed and enrolled patients at Asthma clinic

d. Exclusion criteria: Other respiratory disorders (Tables 1-3).

Table 1: $\% \mathrm{FEV}_{1}$ predicted.

\begin{tabular}{|c|c|c|}
\hline \% $\mathbf{F E V}_{\mathbf{1}}$ of predicted & $\begin{array}{c}\text { No of patients } \\
(\mathbf{n = 9 1 )}\end{array}$ & $\begin{array}{c}\text { Percentage } \\
\text { of total }\end{array}$ \\
\hline Mild or no obstruction $>80 \%$ & 72 & $79.2 \%$ \\
\hline Moderate obstruction $>60 \%$ to $<80 \%$ & 18 & $19.7 \%$ \\
\hline Severe obstruction $<60 \%$ & 1 & $1.1 \%$ \\
\hline Total & 91 & $100 \%$ \\
\hline
\end{tabular}

Table 2: $\mathrm{FEV}_{1}$ : FVC Ratio.

\begin{tabular}{|c|c|c|}
\hline FEV $_{\mathbf{1}}$ : FVC ratio & No. of patients $(\mathbf{N}=\mathbf{9 1})$ & \% of total \\
\hline$>80 \%$ & 72 & $79.2 \%$ \\
\hline 75 to $80 \%$ & 18 & $19.7 \%$ \\
\hline$<75 \%$ & 1 & $1.1 \%$ \\
\hline Total & 91 & $100 \%$ \\
\hline
\end{tabular}


Table 3: PEFR Effects on inhaled bronchodilators on peak expiratory flow rate in patients with acute asthma.

\begin{tabular}{|c|c|}
\hline Number of patients & $\begin{array}{c}\text { Increased PEFR } \mathbf{>} 20 \text { \% after bronchodilator } \\
\text { therapy }\end{array}$ \\
\hline 91 & 91 \\
\hline
\end{tabular}

\section{Discussion}

Pulmonary Function test is done in total 91 patients. Hence three parameters of lung function are taken in to account.
i. \% of $\mathrm{FEV}_{1}$ of predicted
ii. FEV $_{1}$ :FVC Ratio
iii. PEFR and effects of bronchodilators on PEFR

Out of 91 patients, 72 (79.2\%) patients had almost normal pulmonary function. Only 1 patient had severe restriction of pulmonary function and 18 patients had moderate restriction of lung function. All patients shows improvement in PEFR more than $20 \%$ after bronchodilators therapy which is suggestive of reversible air flow limitation.

\section{References}

1. Robert M Kliegmann (2015) Nelson textbook of pediatrics. South Asian edition volume 1: c144

2. Meenu Singh (2011) Asthma in children. ( $1^{\text {st }}$ edn), Jaypee Brothers Medical Publishers, India.

3. International consensus report from national heart lung and blood institute NIH USA (1992) Eur Respir J 5(5): 601-641.

4. Vinay Kumar, Nelso Fausto, Abul Abbas (2014) Robbins and Cotran pathological basis of disease ( $7^{\text {th }}$ edn) pp. 723-727.

5. Batra V, Sethi GR, Sachdev HP (1997) comparative efficacy of jet nebulizer and meter dose inhaler with spacer in treatment of acute asthma. Indian Pediatrics 34(6): 497-503.

6. Harold Royle (1952) X-ray Appearances in Asthma. Br Med J 1(4758): 577-580.
(C) (P) This work is licensed under Creative

To Submit Your Article Click Here: Submit Article

DOI: $10.32474 /$ PAPN.2018.02.000126

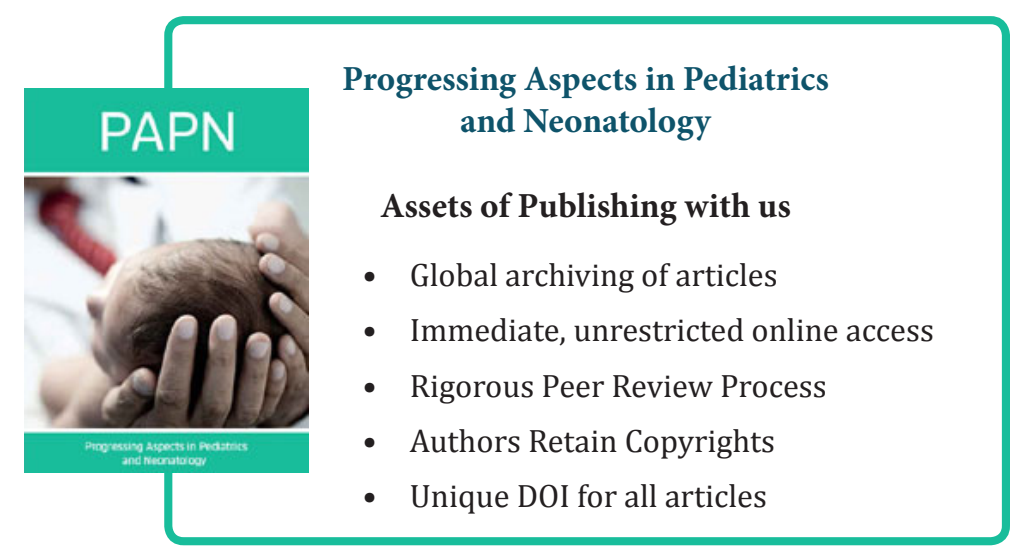

